Bangladesh J. Bot. 43(1): 19-25 (June)

\title{
ETHNOBOTANICAL STUDY ON SOME USEFUL SHRUBS OF ASTORE VALLEY, GILGIT-BALTISTAN, PAKISTAN
}

\author{
Ali Noor*, Surayya Khatoon, Moinuddin Ahmed ${ }^{1}$ and Abdul Razaq ${ }^{2}$ \\ Department of Botany, University of Karachi, Karachi-75270, Pakistan
}

Key words: Ethnobotanical study, Useful shrubs, Astore Valley

\begin{abstract}
In Astore valley, 26 species of plants under 17 genera and 13 families were found to be used as folkmedicine. The study reveals that the villagers from remote area use medicinal plants for the treatment of joint pain, bone fracture, urine problem, asthma, diabetes, blood pressure and for the treatment of other common ailments. The aborigines also use traditional herbal therapy for their live stocks. Because of high destruction pressure of anthropogenic origin, Ephedra gerardiana Wallich ex C.A.Meyer, Berberis spp., Rosa foetida Herrm. and Rhododendron hypenanthum Balf. f. were found threatened.
\end{abstract}

\section{Introduction}

In Pakistan out of 5700 species of plants, about 400 - 600 are medicinal and most of which are confined to the mountain areas (Ali and Qaiser 1986). About 50000 to 60000 Tabibs (practitioners of Greco-Arabic medicine) and a large number of unregistered practitioners scattered in rural and remote hilly areas of Pakistan utilize more remedies for curing of several diseases (Hamayun et al. 2006). Haq and Hussain (1993) stated that Pakistan has about 40000 registered practitioners of traditional medicine and majority of the population, especially in villages getting health care by Tabibs. About $60 \%$ of the total population use the herbal prescriptions of traditional practitioners

Since the British era until to date, Astore Valley, Gilgit-Baltistan, Pakistan has been the largest exporting area of medicinal plants. It is renowned as a realm and a hub of traditional medicinal plants (Kazmi and Siddiqui 1953, Shinwari and Gilani 2003). The mountainous region provides a naturally conductive environment for the medicinal flora. Considerable drugs have been extracted from the flora of the valley and still it possesses a good potential for exploitation and utilization of traditional plants. Details of the topography and climatic condition of the valley has been provided elsewhere (Ali 1995, Noor et al. 2013).

Traditional practices followed by the local communities of Astore valley need proper documentation. So, the present study was undertaken to record the indigenous knowledge on plants of the Astore valley and to encourage their sustainable use and conservation.

\section{Materials and Methods}

Comprehensive field surveys were conducted throughout the Astore valley $\left(34.8^{0}-35.8^{0} \mathrm{~N}\right.$ and $74.4^{0}-75.2^{0}$ E, altitude 1200- 8126 m MSL, Nanga Parbat), from April to October between 2005 and 2009. The ethnobotanical information was collected by interviewing the local people. For the purpose, a questionnaire was prepared to record information from inhabitants including local names of ethnobotanically important plants, the harvesting and processing techniques, and the

*Author for correspondence. <alinoor_na@yahoo.com>. ${ }^{1}$ Department of Botany, Federal Urdu University of Arts, Science and Technology, Karachi-75300, Pakistan. ${ }^{2}$ Department of Biological Science, Karakorum International University, Gilgit-Baltistan, Pakistan. 
mode of administration of these plants to treat particular ailments along with other ethnobotanical uses. Importance was given to those people who have knowledge about the uses of plants for health care, like local Hakims and particularly the aged people whose knowledge was respected by the local people.

Voucher plant specimens of ethnobotanical interests were collected from different localities of the study area. All the collected plant specimens were properly pressed, dried and mounted on herbarium sheets. The identification was made with the help of the Flora of Pakistan (Nasir and Ali 1970-1987, Nasir and Ali 1988-1998, Ali and Qaiser 1993-2010), Flora Iranica (Rechinger 1975-2001) and other available pertinent literature and also by comparing with the authentically identified specimens present in the Karachi University Herbarium (KUH). The identified voucher specimens were deposited in the same herbarium (KUH).

\section{Results and Discussion}

Twenty six shrub species belonging to 17 genera and 13 families are documented for their ethnobotanical uses (Table 1). The family Rosaceae with 10 species is reported as the largest representative of medicinal plants in the study area which is followed by Grossulariaceae with 3 species, Ephedraceae and Papilionaceae each with two and the remaining 9 families with one species in each.

Four species viz. Rhododendron hypenanthum Balf. f. (Fig. 1), Ephedra gerardiana Wallich ex C.A.Meyer (Fig. 2), Berberis orthobotrys Bien. ex Aitch. (Fig. 3) and Rosa foetida Herrm. are observed as extensively exploited by the local people for their various ethnobotanical uses (Table 1 ) without any restrictions and following any conservation strategy. As a result, these species are seen to be threatened in the natural habitat of the study area. Ribes nigrum L. is also a threatened ethnobotanically used plant of Astore valley. In the present study, it is observed that the knowledge of medicinal plants and their methods of usage are confined to aged persons of mostly above 50 -60 years old. According to Noor et al. (2013) the traditional knowledge and the percentage of traditional cure system in Astore valley are rapidly decreasing. However, about 20 30 percent people of remote and upper villages are found to be dependent on traditional cure system for their ailments and for their livestock health care. In down and central villages 10 - 15 percent people use the traditional system of treatment for their ailments. This is likely due to the lack of belief of young generation on the traditional medicine system and use of allopathic medicines by them, because of their availability and efficacy.

There is a great need to create awareness among the indigenous communities about threatened medicinal plants. The present study on the economically and medicinally important plants of the study area will help to draw the attention of the government, NGOs and local communities to the basic factors which are directly involved in depleting the plant resources and to develop plans for their protection and sustainable uses in the area. In addition, local cultivation of medicinal plants and other economically important species can play an important role in the economic development of the area. For example, Hippophae rhamnoides subsp. turkestanica Rousi (Fig. 4) is a common ethnobotanically used plant of the study area which can be useful source of income, if small industries are developed in locally and its fruit is used for preparing jam and syrup. It is useful for cough, blood pressure and as well as energetic. If proper understanding is developed among the aborigines, it may be helpful to generate their income through producing enough medicinal raw material for the traders and pharmaceutical companies. 


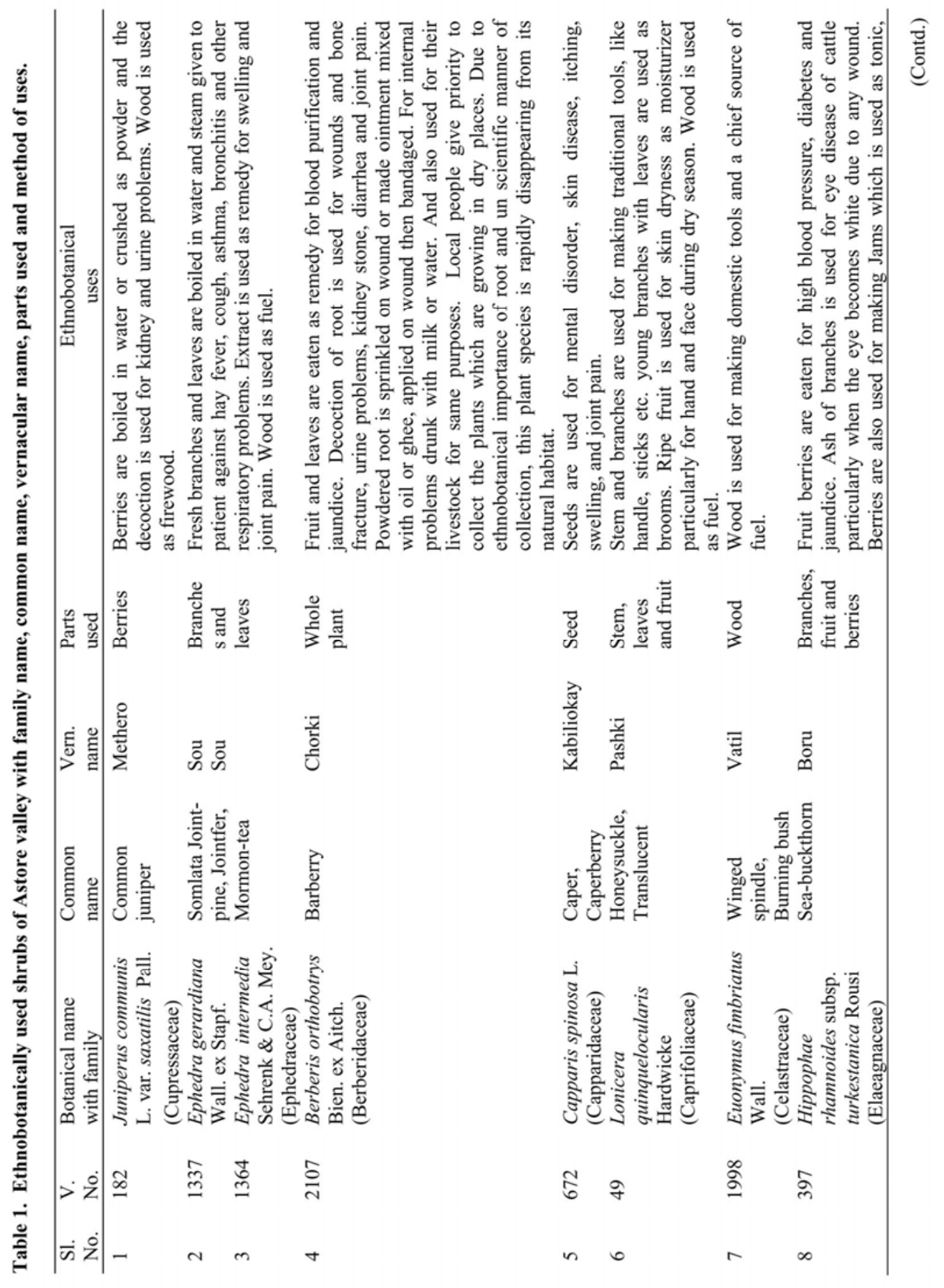




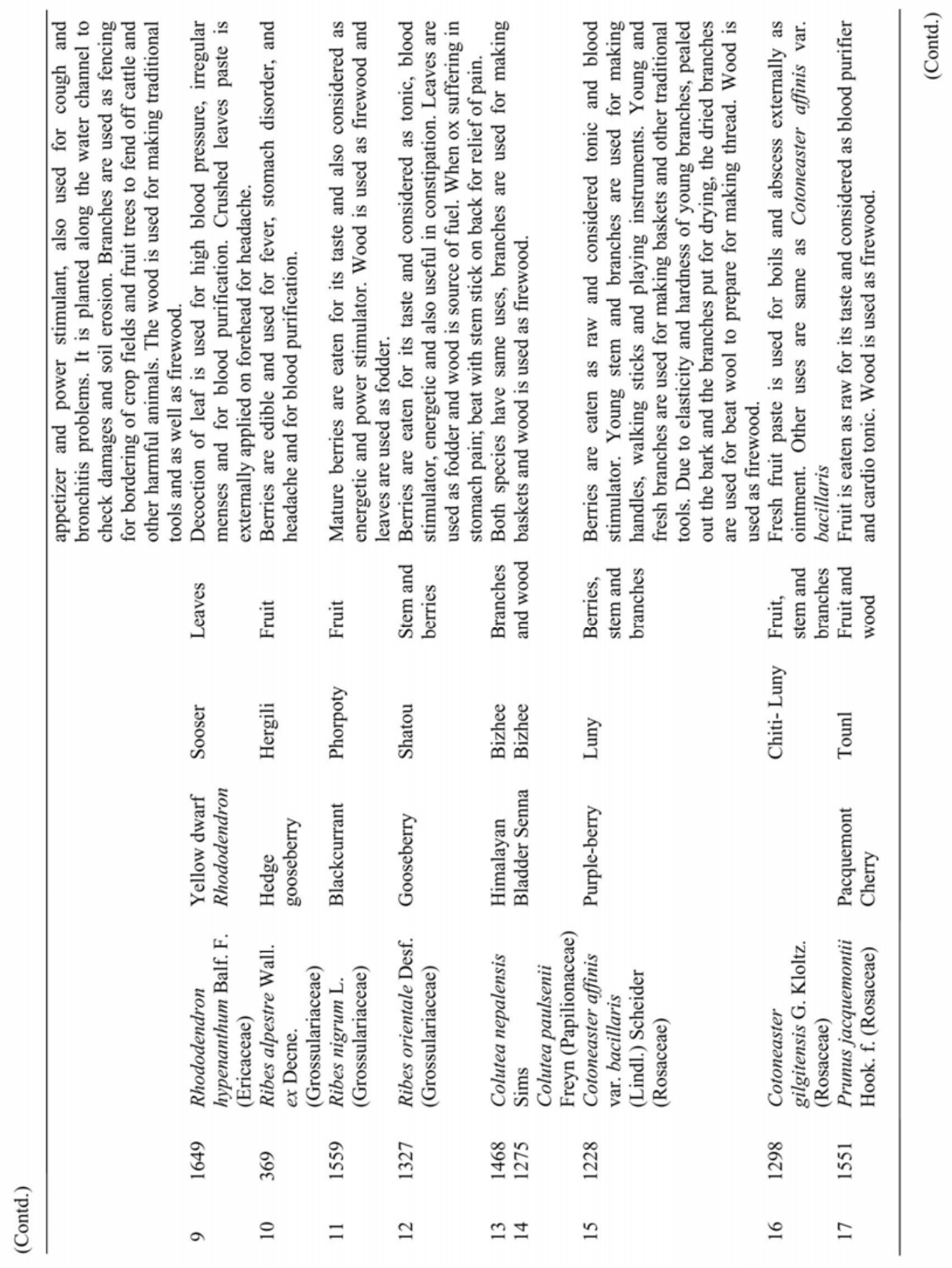




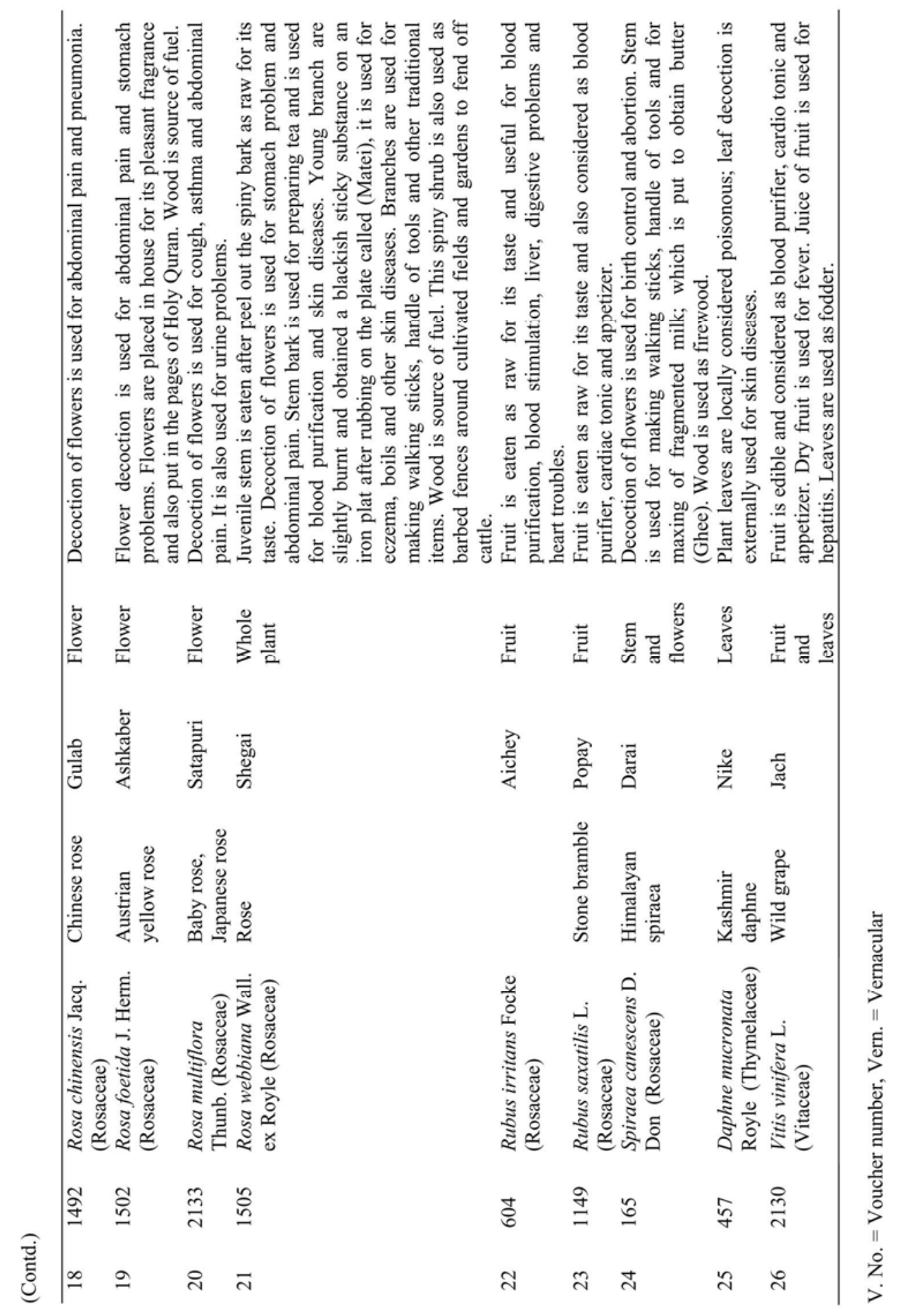



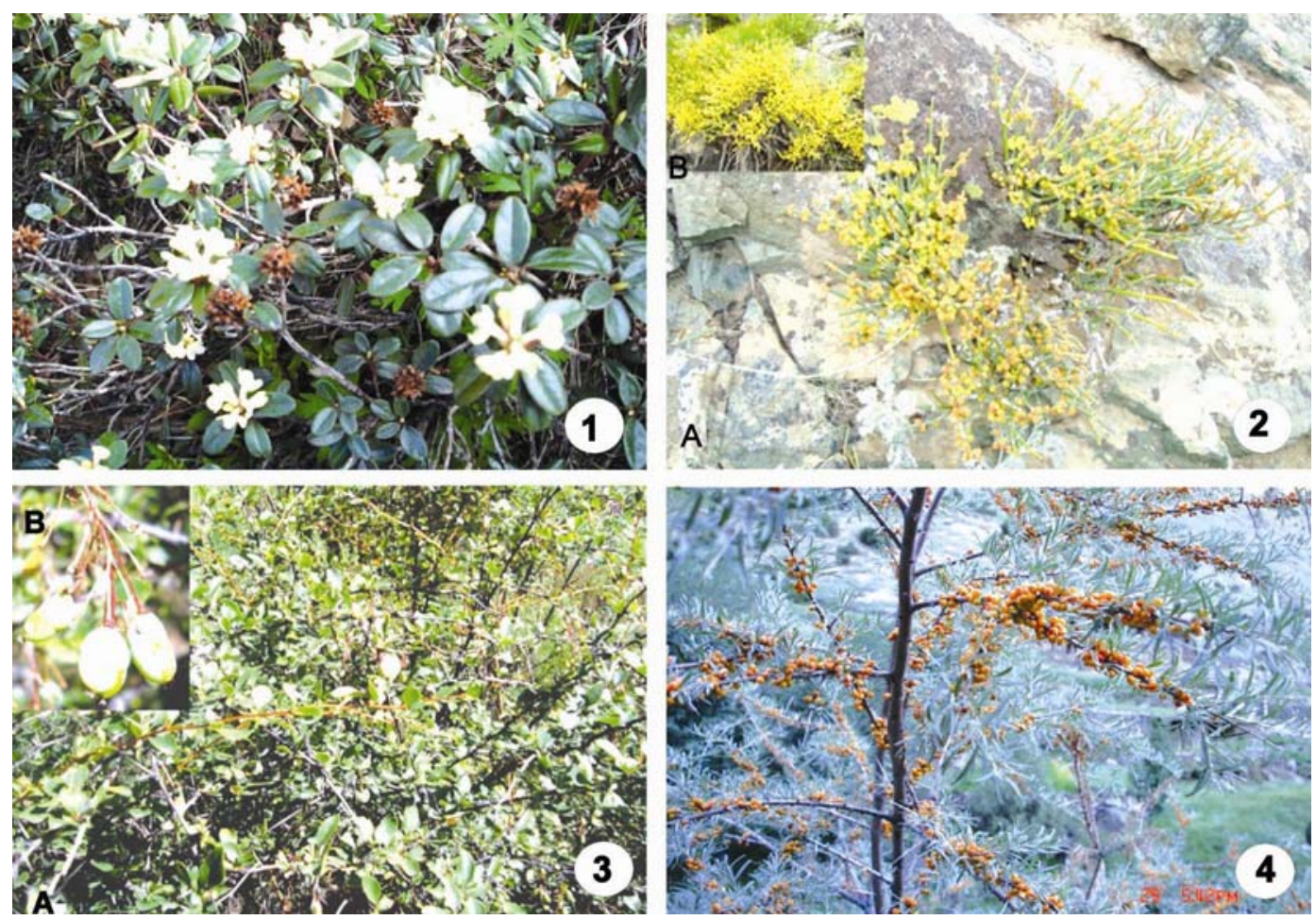

Figs 1-4: Threatened medicinal plants of Astore valley. 1. Rhododendron hypenanthum. 2. Ephedra gerardiana (A-habit, B-Flower). 3. Berberis orthobotrys (A-branches, B-fruit). 4. Hippophae rhamnoides subsp. turkestanica.

Due to the expansion of agricultural land, habitat degradation, sliding, over exploitation and unsustainable uses of plants in the study area a number of taxa has been observed to be disappeared from natural habitats. There is a strong need to take immediate steps on urgent basis to conserve their population in their habitat.

\section{Acknowledgements}

Essa Khan, a local Herbalist and the people of the villages Peerjot, Kalalot, Gorikot and Eidgah are thankfully acknowledged for extending their help for collecting medicinal plants and other ethnobotanical information.

\section{References}

Ali M 1995. Map of Northern Areas of Pakistan. Fine Books Printers, Lahore.

Ali SI and Qaiser M 1986. A phytogeographical analysis of phanerograms of Pakistan and Kashmir. Proc. of Royal Soc. Edingburgh 89B: 89-101.

Ali SI and Qaiser M (Eds.) 1993-2010. Flora of West Pakistan. Nos. 194-217 Karachi.

Haq IU and Hussain M 1993. Medicinal plants of Mansehra District. Hamdard Medicus 34: 63-99.

Hamayun M, Khan SA, Kim HY and Leechae IJ 2006. Traditional knowledge and ex situ conservation of some threatened medicinal pants of Swat Kohistan. Pak. J. Bot. 38(2): 205-209. 
Kazmi MA and Siddiqui IA 1953. Medicinal plants of Astore and Upper Guraiz Valleys. Pak. J. For. Peshawar 3:186-212.

Nasir E and Ali SI (Eds) 1970-1987. Flora of West Pakistan, Nos. 1-181 Islamabad, Karachi.

Nasir Y and Ali SI (Eds) 1988-1998. Flora of West Pakistan, Nos. 182-190. Islamabad, Karachi.

Noor A, Khaoon S and Ahmed M, 2013. Ethnobotanical studies on some useful trees of Astore valley (GilgitBaltistan) Pakistan with particular reference to medicinal uses. Int. J. Biol. Biotech. 10(4): 565-572.

Noor A and Khatoon S 2013. Analysis of vegetation pattern and soil characteristics of Astore valley GilgitBaltistan. P.J. Bot. 45(5): 163-1667.

Rechinger KH 1975-2001. Flora Iranica. Nos.1-174. Naturhist. Museum, Graz.

Shinwari ZK and Gilani SS 2003. Sustainable harvest of medicinal plants at Bulashbar Nullah, Astore (Northern Pakistan). J. Ethnopharmaco. 84: 289-298.

(Manuscript received on 13 October, 2012; revised on 30 March, 2014) 